\title{
Closed total (pan-talar) dislocation of the talus with delayed presentation: a rare case report and review of the literature
}

\author{
Geç bulgu veren kapalı total (pantalar) talus çıkığı: \\ Nadir bir olgu sunumu ve literatür değerlendirmesi
}

Rajesh DULANI, Sandeep SHRIVASTAVA, Sameer DWIDMUTHE, Ravi PUROHIT

Major fractures and dislocation of the talus and peritalar joint are uncommon. We present here a very rare case of injury with delayed presentation of closed total talus dislocation with fractured medial malleolus and posterior talar tubercle fracture. This report analyzes previous reports in the literature and the proposed treatment.

Key Words: Total talus dislocation; delayed presentation; closed injury.
Talus ve peritalar eklemin majör kırık ve çıkıkları nadirdir. Bu yazıda, gecikmeli başvuran, kapalı total talus çıkığ1, mediyal malleol kırığı ve posterior talar tüberkül kırığ1 yaralanmalı, nadir görülen olgu sunuldu. Bu yazıda, literatürdeki daha önceki sunum ve önerilen tedavi değerlendirildi.

Anahtar Sözcükler: Total talus çıkı̆̆ı; gecikmeli başvuru; kapa11 yaralanma.
Major fractures and dislocation of the talus and peritalar joint are uncommon. The incidence of fracture of the talus ranges from $0.1 \%$ to $0.85 \%$ of all fractures, ${ }^{[1]}$ and $6 \%$ of injuries affect the ankle and foot. ${ }^{[2]}$ Total dislocation of the talus is an extremely rare injury. There are few reports of total dislocation of the talus in the literature, with the majority being an open injury. There are two major series of nine cases each by Detenbeck et al. ${ }^{[3]}$ and Coltart ${ }^{[2]}$ of total talar dislocation, with the majority being open type.

We present here a very rare case of injury with delayed presentation of closed total talus dislocation with fractured medial malleolus and posterior talar tubercle fracture. This report analyzes previous reports in the literature and the proposed treatment.

\section{CASE REPORT}

A 19-year-old healthy male, with height of $1.75 \mathrm{~m}$ and weight of $80 \mathrm{~kg}$, presented in our outpatient department with pain, swelling and deformity of his left ankle for three days after a fall from a height of about $4.57 \mathrm{~m}$. The physical examination revealed swell- ing over the left foot and ankle and varus deformity of the forefoot (Fig. 1). There was no breach in the skin above the ankle and foot. There was no associated injury. On palpation, bony swelling was present below the lateral malleolus with hollowness below the medial malleolus. The dorsalis-pedis and posterior tibial pulsations were palpated as normal. There was no hypoesthesia over the foot or ankle. There was no sign of hyper- laxity of other joints. On radiographic examination of the ankle and foot (Figs. 2a-c), the talus was found completely dislocated from the ankle and subtalar and talonavicular joints. The talus lay horizontally just below the lateral malleolus, and there was associated fracture of the medial malleolus and posterior tubercle of the talus.

The patient was taken to emergency for reduction of the dislocation. Medial exposure was used. The talus was approached through the window of the fractured medial malleolus, and was found beneath the lateral malleolus with no soft tissue attachment. Reduction was achieved by traction through a temporary transverse Steinman pin placed through the calcane-
Deemed Üniversitesi Datta Meghe Tıp Bilimleri Enstitüsü, J N Tip Koleji,

Sawangi(m), Wardha, Maharastra, Hindistan. 


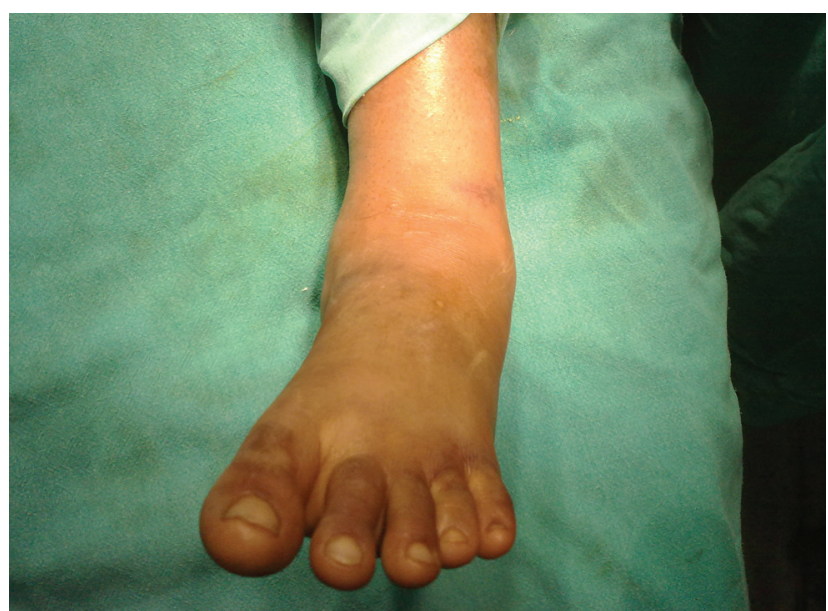

Fig. 1. Preoperative clinical photograph of the foot showing slight forefoot varus and edema.

(Color figures can be viewed in the online issue, which is available at www.tjtes.org)

um. The medial malleolus was fixed with a Kirschner (K)-wire. A percutaneous K-wire from the heel was used to stabilize the subtalar and ankle joints. Similarly, a percutaneous K-wire was used to stabilize the talonavicular joint (Fig. 3). After removing the sutures, a non-weight-bearing below-knee cast was applied for six weeks. After six weeks, the cast and percutaneous K-wires were removed. The patient's left ankle was kept in non-weight-bearing with gradual mobilization for another six weeks. The patient was reviewed after six months and one year, and was found to have $10^{\circ}$ and $40^{\circ}$ of pain-free ankle dorsiflexion and plantarflexion, respectively. Radiographic examination showed no sign of avascular necrosis of the talus (Fig. 4).

\section{DISCUSSION}

Total dislocation of the talus has been reported as $0.06 \%$ of all dislocations and $2 \%$ of all talar fractures. ${ }^{[4]}$

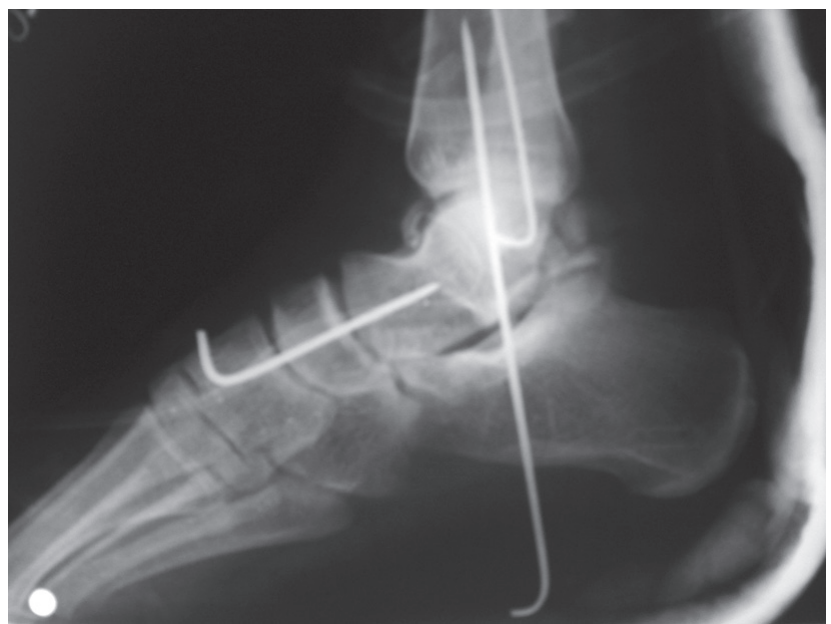

Fig. 3. Postoperative lateral X-ray showing the reduced ankle with percutaneous K-wire fixed for the talonavicular joint and subtalar and ankle joints.
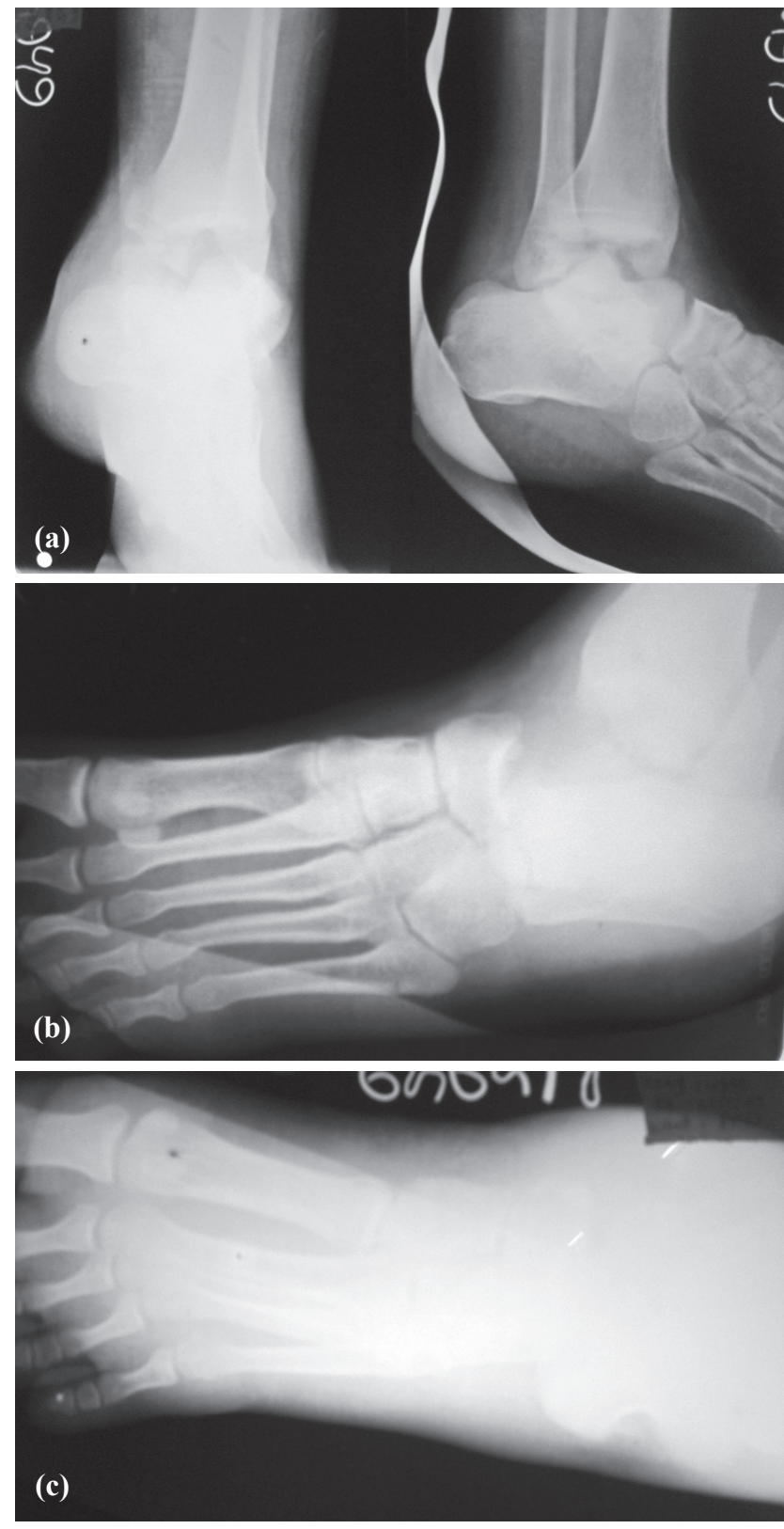

Fig. 2. (a) Anteroposterior X-ray of the ankle showing the talus below the lateral malleolus. The lateral X-ray of the ankle shows complete dislocation of the talus from the ankle and subtalar joint and the talus anterior to the lateral malleolus. (b) Anteroposterior (right) and (c) oblique (left) X-ray of the foot of the same patient showing complete dislocation of the talonavicular joint.

Fabricus first described complete dislocation of the talus treated by talectomy in $1608 .{ }^{[5]}$ One of the largest series of 228 talus injuries was published by Coltart, ${ }^{[2]}$ who was the first to propose a concise classification of talus injury as fractures, fracture - dislocations, dislocation, miscellaneous injuries, and subtalar dislocation. In this series, nine cases of total dislocation of the talus were reported and most were open type. In the report by Detenbeck et al.,${ }^{[3]}$ seven of nine cases of total dislocation of the talus were of open type. One of 


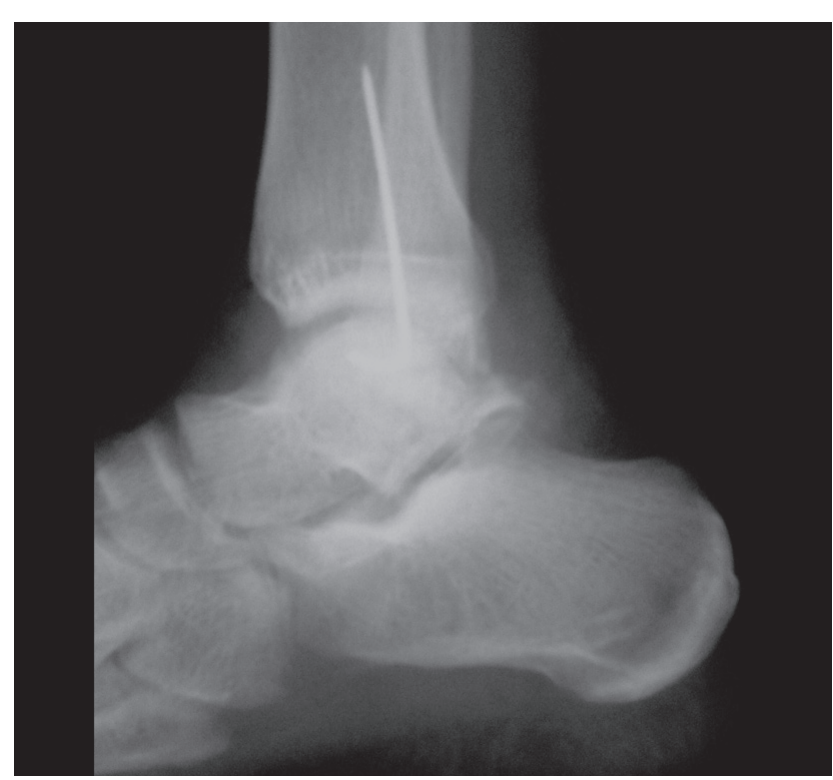

Fig. 4. One year after reduction, lateral X-ray of the ankle shows well-maintained density of the talus.

the closed total dislocations was with fracture of the neck and body of the talus and another was with comminuted fracture of the body of the talus.

In a review of 58 major injuries of the talus by Kenwright et al., ${ }^{[5]}$ there were two cases of total dislocation of the talus. The authors reported that in both cases, the talus was displaced on to the dorsolateral aspect of the foot, but there is no report as to whether total dislocation was of closed or open type.

In a report by Newcomb et al., ${ }^{[6]}$ a 45 -year-old man with head injury had complete dislocation of the talus of closed type. He was treated within one hour of injury. Closed reduction was possible with traction by means of a K-wire through the calcaneum and countertraction with a Steinman pin through the proximal portion of the tibia.

In a report by Segal et al., ${ }^{[7]}$ a 50 -year-old man was shown on initial roentgenogram to have a dislocation of the ankle with the talus displaced anteriorly. Stress roentgenogram revealed unrecognized talonavicular and talocalcaneal subluxation when the foot was in internal rotation with varus stress applied to its fore part. There was no frank dislocation of the talonavicular or subtalar joint in this case.

Normally, the talus is held in the ankle mortise by its own shape assisted by attachment of the neck and head, the talocalcaneal ligament, the strong posterior talofibular ligament, and the posterior and deep fibers of the medial ligament of the ankle. ${ }^{[2]}$ The mechanism for total dislocation of the talus as suggested by Clotart is extreme plantar flexion and inversion of the foot. He suggested that extreme plantar flexion first leads to complete forward dislocation of the whole foot at the ankle, and forceful adduction and inversion of the foot then leads the talus to rotate $90^{\circ}$ on its vertical and longitudinal axes. The foot itself the recoils below tibia but the talus is let displaced in its rotated position outside and front ankle joint. ${ }^{[2]}$ In a review of 42 cases of total dislocation of the talus by Leitner, ${ }^{[8]}$ subtalar dislocation was considered as a preliminary stage in total dislocation of the talus. Total dislocation of the talus results from excessive supination or excessive pronation, and accordingly, the dislocated talus lies either laterally or medially. A first-degree supination injury results in medial subtalar dislocation, a second-degree supination results in medial subtalar dislocation with talocrural subluxation, and a third-degree supination injury results in total lateral dislocation of the talus.

The majority of total talar dislocations are open injuries $^{[2,3,4,9]}$ because of the severity of trauma. In the majority of cases, the talus has dislocated forward and laterally so that it lies in front of the lateral malleolus and is rotated $90^{\circ}$ in both its vertical and longitudinal axis. $[2,3,5,6,8]$ In our case, the talus lay in front of the lateral malleolus but was not rotated on any axis; moreover, the patient presented three days after the injury.

Treatment recommendations in the case of total dislocation of the talus vary. Some authors recommend, because of possible infection, damage to the talar vascularity and consequent avascular necrosis, primary talectomy with tibiocalcaneal arthrodesis, even in the case of a closed talar dislocation. ${ }^{[3]}$ However, primary talectomy affects hindfoot function and limits subsequent reconstructive options..$^{[9,10]}$ In our opinion, relocation of the talus should be recommended in closed total dislocation of the talus, even in the case of delayed presentation, as in our case.

\section{REFERENCES}

1. Fortin PT, Balazsy JE. Talus fractures: evaluation and treatment. J Am Acad Orthop Surg 2001;9:114-27.

2. Coltart WD. Aviator's astragalus. J Bone Joint Surg $\mathrm{Br}$ 1952;34-B:545-66.

3. Detenbeck LC, Kelly PJ. Total dislocation of the talus. J Bone Joint Surg Am 1969;51:283-8.

4. Gulan G, Sestan B, Jotanovic Z, Madarevic T, Mikacevic M, Ravlic-Gulan J, et al. Open total talar dislocation with extrusion (missing talus). Coll Antropol 2009;33:669-72.

5. Kenwright J, Taylor RG. Major injuries of the talus. J Bone Joint Surg Br 1970;52:36-48.

6. Newcomb WJ, Brav EA. Complete dislocation of the talus. J Bone Joint Surg Am 1948;30A:872-4.

7. Segal D, Wasilewski S. Total dislocation of the talus. Case report. J Bone Joint Surg Am 1980;62:1370-2.

8. Leitner B. The mechanism of total dislocation of the talus. $\mathrm{J}$ Bone Joint Surg Am 1955;37-A:89-95.

9. Assal M, Stern R. Total extrusion of the talus. A case report. J Bone Joint Surg Am 2004;86-A:2726-31.

10. Smith CS, Nork SE, Sangeorzan BJ. The extruded talus: results of reimplantation. J Bone Joint Surg Am 2006;88:241824. 